\title{
Finite element analysis on permeability of cut-off wall for landfill
}

\author{
Guozhong Dai, Jiajing Xu, Shujin Li, Xiongwei Li, Guicai Shi, Weicheng Shi \\ School of Civil Engineering \& Architecture, Changzhou Institute of Technology, China
}

\begin{tabular}{l}
\hline Article Info \\
\hline Article history: \\
Received Jul 5, 2020 \\
Revised Jul 20, 2020 \\
Accepted Aug 4, 2020 \\
\hline Keywords: \\
Computer analysis \\
Cut-off wall \\
Finite element method \\
Gradient \\
Permeability
\end{tabular}

\begin{abstract}
Finite element method is an efficient numerical calculation method based on information technology, which can be used to solve complex equations in various problems. At present, the finite element method is mainly used to deal with seepage problems in dams, while there is less study on seepage in landfill. In this paper, finite element method is used to analyze the seepage of cut-off wall of a landfill in Jiangsu Province, and the movement of landfill leachate in cut-off wall under different conditions is simulated. The simulation results show that The cut-off wall can effectively slow down the seepage velocity of leachate; Under different conditions, the maximum gradient of the cut-off wall are 18.68 and 13.84 respectively, which conforms to Chinese national standard. Therefore, the design of cut-off wall is safe and reasonable, and filtration erosion will not occur; This simulation method combined with information technology can provide new solutions and ideas for other projects to verify safety and rationality.
\end{abstract}

This is an open access article under the CC BY-SA license.

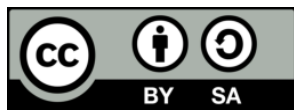

\section{Corresponding Author:}

Guozhong Dai

School of Civil Engineering \& Architecture

Changzhou Institute of Technology

Qinglong Street, Tianning District, Changzhou City, Jiangsu Province, China

Email: daigz@czu.cn

\section{INTRODUCTION}

Urban garbage contains many harmful substances and bacteria, so measures should be taken to prevent it from polluting the environment [1-3]. Sanitary landfill has been widely used in China due to its low cost and mature technology [4]. Due to the poor permeability of natural soil layer, an effective antiseepage system is necessary to be established to prevent leachate leakage [5]. Meantime, it is important to verify the impermeability of the anti-seepage system. With the development of information technology, now many problems can be solved by professional software [6]. These software make the finite element method, a powerful and popular method proven to be an efficient mean to solve practical engineering problems. Finite element method is a numerical simulation method, which is mainly used to solve various continuous problems, such as seepage problems [7, 8]. G. X. Zhang et al. [9] considered the influence of pore pressure and optimized the infiltration load formula of finite element method. Compared with other methods, the results show that this method can reduce errors. Fukuchi et al. [10] proposed an equivalent KZ flow method by using the powerful calculation function of computer, which can significantly improve the accuracy for locating free surface location. L. Shi et al. [11] improves the finite-element-based limit equilibrium method (FELE) and regards seepage force as body strength, which makes FELE insensitive to grid. D.M. Pedroso [12] discussed a method based on the enrichment of finite elements, which can accurately model seepage under complex boundary conditions. S. S. Athani et al. [13] considered coupling effect and used finite element method to analyze seepage and stability of fill dam, the results show that the fill dam is safety. 
Using numerical simulation to solve seepage problems in landfill is still a relatively new method in this field. Computer simulation of practical engineering problems can intuitively predict the effect of engineering and reduce the amount of calculation [14]. At present, the analysis of seepage problems is mainly focused on seepage of dams [15], but the seepage simulation of landfill is rare. In this paper, the finite element method was used to analyze the permeability of the cut-off wall for landfill, and two possible boundary conditions were selected to verify the cut-off wall's safety and rationality. The simulation results show that the cut-off wall can effectively slow down the infiltration rate of leachate, leachate seeps around the bottom of the wall under the action of the cut-off wall, and a small amount of leachate directly passes through the wall. Condition 1 has a higher leachate level than condition 2, which leads to an overall increase of saturation line and a larger seepage velocity. The simulation results agree with the theory. The gradient of the cut-off wall is within the safe range, And the design of cut-off wall can provide theoretical support for practical engineering, and the way using finite element method to simulate seepage of cut-off wall has guiding significance for optimizing related projects.

\section{GENERAL SITUATION OF ENGINEERING}

A landfill, located in Jiangsu Province, China, is selected for seepage analysis. The designed storage capacity of the landfill is $3 \times 10^{6} \mathrm{~m}^{3}$, the depth of the landfill is $14 \mathrm{~m}$, the perimeter of the landfill is $2000 \mathrm{~m}$, and the thick of cut-off wall is $1 \mathrm{~m}$. According to geological report, the soil layers in the excavation depth of the landfill are miscellaneous fill, clay layer, silty clay with cohesive silt, silt clay and clay. And the bottom of the landfill is impermeable clay layer (the burial depth is about $16 \mathrm{~m}$ ). The physical and mechanical parameters of each soil layer and cut-off wall are shown in Table 1.

Table 1. The physical parameters values of each material in the landfill

\begin{tabular}{cccccc}
\hline Material & $\begin{array}{c}\text { Miscellaneous } \\
\text { fill }\end{array}$ & Clay & $\begin{array}{c}\text { Silty clay with } \\
\text { cohesive silt }\end{array}$ & $\begin{array}{c}\text { Silty } \\
\text { clay }\end{array}$ & $\begin{array}{c}\text { Clay } \\
\text { Wall }\end{array}$ \\
\hline Compression modulus/Es/(MPa) & 6 & 11 & 11 & 8 & 11 \\
Horizontal permeability & $1.20 \times 10^{-5}$ & $9.40 \times 10^{-}$ & 10 & 200 \\
coefficient/kH/(m/s) & & 10 & $4.42 \times 10^{-7}$ & $\begin{array}{c}8.03 \times 10^{-} \\
9\end{array}$ & $9.30 \times 10^{-}$ \\
Water content/ $/(\%)$ & 0.295 & 0.255 & 0.294 & 0.239 & 0.231 \\
$4 \times 10^{-110}$ & 0.702 \\
Average thickness of soil layer/h/(m) & 1.7 & 3.6 & 3.8 & 4.2 & 10 \\
\hline
\end{tabular}

Note: The wall thickness is $1 \mathrm{~m}$ and the wall height is $15 \mathrm{~m}$.

The vertical cut-off wall is composed of PBFC anti-seepage slurry containing glass fibers [16, 17], and the slurry formula is as follows: cement $180 \sim 240 \mathrm{~kg} / \mathrm{m}^{3}$, bentonite $220 \sim 260 \mathrm{~kg} / \mathrm{m}^{3}$, fly ash $180 \sim 200$ $\mathrm{kg} / \mathrm{m}^{3}$, polyvinyl alcohol $3 \sim 6 \mathrm{~kg} / \mathrm{m}^{3}$, soda $5 \sim 8 \mathrm{~kg} / \mathrm{m}^{3}$, glass fiber $0.6 \sim 1.2 \mathrm{~kg} / \mathrm{m}^{3}$, Polycarboxylate superplasticizer $2 \sim 3 \mathrm{~kg} / \mathrm{m}^{3}$. Since the permeability coefficient of this slurry is $0.12 \sim 0.98 \times 10^{-9} \mathrm{~m} / \mathrm{s}$, the slurry can effectively slow down the leakage rate of landfill leachate into the surrounding soil. And it can effectively block metal ions, ammonia nitrogen compounds and organic matters, the blocking rate of heavy metal ions, ammonia nitrogen compounds and organic matters are over $99.90 \%$, 98.00\% and $83.00 \%$ respectively. This meets the requirements of landfill on impermeability of cut-off wall. Finally, the cut-off wall of landfill is constructed by high-pressure rotary jet grouting method.

\section{CALCULATION MODEL}

\subsection{Differential equation of seepage flow}

Steady seepage is based on Darcy's law, Darcy's law and continuity equation can be combined to obtain stable seepage differential equation. When soil and water are incompressible, the stable seepage differential equation is [18]:

$$
\frac{\partial}{\partial x}\left(k_{x} \frac{\partial h}{\partial y}\right)+\frac{\partial}{\partial y}\left(k_{y} \frac{\partial h}{\partial h}\right)=0
$$

The numerical simulation software uses the finite element method to solve the seepage differential equation, and software will transform the seepage differential equation into the finite element form. In this time, the Galerkin method with weighted residuals can be used to transform differential equations into linear equations in finite element form [19]:

IAES Int J Rob \& Autom, Vol. 10, No. 1, March 2021: $59-67$ 


$$
\begin{gathered}
\tau \int_{A}\left(\left[\left[\frac{\partial<N>}{\partial x} \frac{\partial<N>}{\partial Y}\right]\right]\left[\begin{array}{cc}
C_{11} & C_{12} \\
C_{21} & C_{22}
\end{array}\right]\left[\begin{array}{c}
\frac{\partial<N>}{\partial X} \\
\frac{\partial X}{\partial y}
\end{array}\right]\right) \mathrm{d} A\left\{\begin{array}{c}
H_{1} \\
H_{2}
\end{array}\right\}+ \\
\tau \int_{\mathrm{A}}\left(\lambda<\mathrm{N}>^{\mathrm{T}}<\mathrm{N}>\right) \mathrm{dA}\left\{\begin{array}{l}
\mathrm{H}_{1} \\
\mathrm{H}_{2}
\end{array}\right\}, \mathrm{t}=\mathrm{q} \tau \int_{\mathrm{L}}\left(<\mathrm{N}>^{\mathrm{T}}\right) \mathrm{dL}
\end{gathered}
$$

In this formula, $C_{11}, C_{12}, C_{21}$ and $C_{22}$ are components in horizontal and vertical directions of permeability coefficient, $C_{11}$ is $k_{x} \cos 2 \alpha+k_{y} \sin 2 \alpha, C_{12}$ and $C_{21}$ are $k_{x} \cos \alpha+k_{y} \sin \alpha, C_{22}$ is $k_{x} \sin 2 \alpha+k_{y} \cos 2 \alpha$, and $\alpha$ is the angle between permeability direction and horizontal plane. $H_{l}, H_{2}$ is the node head; $\langle N\rangle$ is an interpolation function vector, and its partial derivatives are unit gradients in horizontal and vertical directions respectively; $Q$ is the boundary flow; $\tau$ Is the unit thickness; $\lambda$ is $m_{w} \gamma_{w}$ in transient seepage; $t$ is time; $A$ is the sum of unit areas; $L$ is the sum of the boundary lengths. There is no need to consider the time factor when analyzing steady seepage, so $\left\{\begin{array}{l}H_{1} \\ H_{2}\end{array}\right\}, t$ in second term is 0 , and the formula (2) becomes, (3) is the finite element form of steady seepage equation.

$$
\tau \int_{A}\left(\left[\left[\frac{\partial<N>\partial<{ }^{2}}{\partial x} \frac{\partial<N>}{\partial Y}\right]\right]\left[\begin{array}{ll}
C_{11} & C_{12} \\
C_{21} & C_{22}
\end{array}\right]\left[\begin{array}{c}
\frac{\partial<N>}{\partial X} \\
\frac{\partial<N>}{\partial y}
\end{array}\right]\right) \mathrm{d} A\left\{\begin{array}{c}
H_{1} \\
H_{2}
\end{array}\right\}+\left\{\begin{array}{l}
\mathrm{Q}_{1} \\
\mathrm{Q}_{2}
\end{array}\right\}
$$

\subsection{Analysis type}

The SEEP/W module of GeoStudio was used to studied the seepage situation of leachate, which can simulate the saturation line and seepage field of cut-off wall. The saturation model is suitable for the situation that soil materials are always below the water level line, but in practical engineering, seepage mainly exists below the saturation line, while almost no seepage occurs above the saturation line [20]. Therefore, the saturated/unsaturated seepage constitutive model can finally determine the positions of saturated and unsaturated areas after iteration, and the results are more realistic. Hence, the saturated/unsaturated seepage constitutive model was selected to calculate and iterate the location of saturated and unsaturated regions, and the results are more in line with the actual situation. When the saturated/unsaturated model is selected, the curvilinear relation between matric suction, volumetric water content and permeability coefficient should be provided in the software. At this point, the function type of soil water characteristic curve is volume water content data point function, and the estimation method can choose the sample function provided by the software; At the same time, the permeability coefficient function type is selected as the permeability coefficient data point function, and the estimation method is frelund \& Xing method, which can be used under full matrix suction. Using the frelund \& Xing method, we need to get the data of fitting parameters $\alpha$, $n, m$, which can be obtained by software by fitting the data of permeability coefficient. At last, the curve will be estimated by the function of the finite element software When the permeability coefficient is $4 \times 10^{-10} \mathrm{~m} / \mathrm{s}$, the soil-water characteristic curve and permeability coefficient function curve of the cut-off wall are shown in Figure 1 and Figure 2.

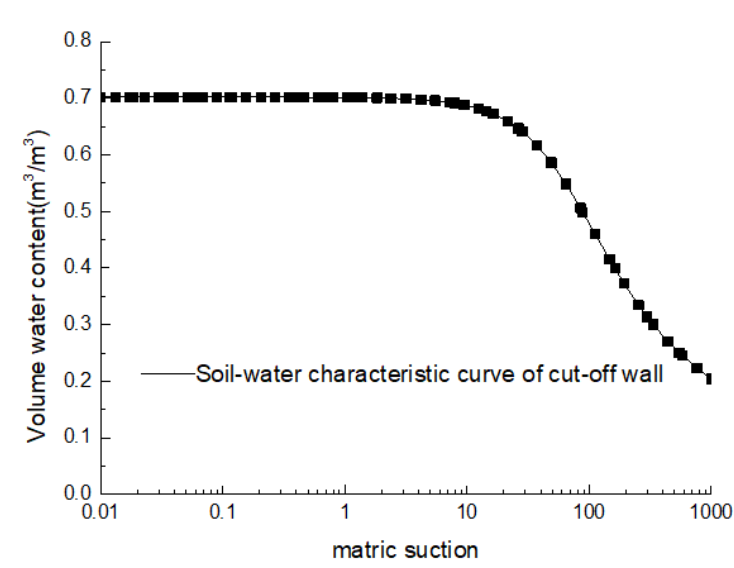

Figure 1. Soil-water characteristic curve of cut-off wall

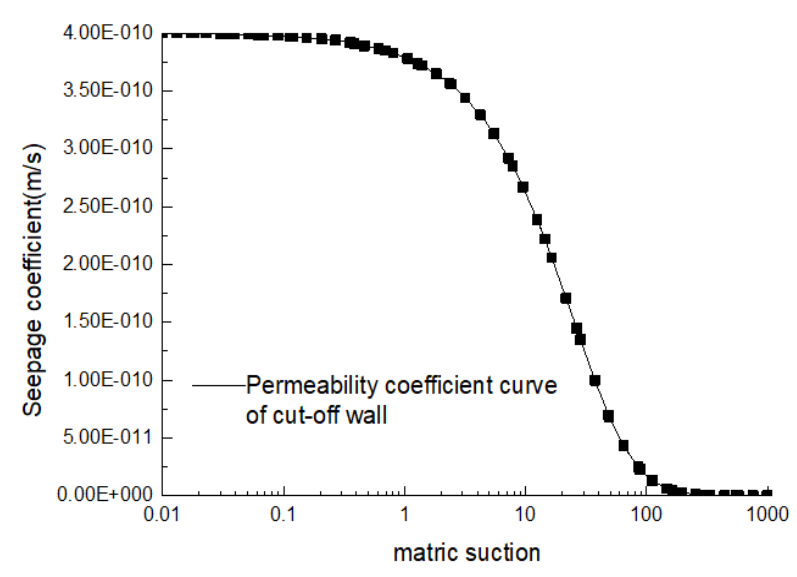

Figure 2. Permeability coefficient function of cut-off wall 
From Figure 1, we can find that the water content of the cut-off wall decreases smoothly with the increase of matrix suction, then drops rapidly when the matrix suction reaches a certain value, the permeability coefficient also shows a similar tend. This tend indicates that the pore size distribution in the cut-off wall is relatively uniform, as the moisture in the pore space can only be released when the matric suction is loaded to a certain value. The initial water content decreases slowly with the increase of matrix suction, which indicates that the cut-off wall has good anti-seepage performance.

\subsection{Model condition}

According to the landfill condition, the section to be analyzed is relatively flat, so the soil layers can be regarded as rectangles when modeling. Meanwhile, the specific size and boundary conditions of each component in the model can be determined by the content of investigation report and construction organization design. The overall height and length of the model are $30 \mathrm{~m}$ and $20 \mathrm{~m}$ respectively. And the cutoff wall is $15 \mathrm{~m}$ in height and $1 \mathrm{~m}$ in width; the depth of landfill is $14 \mathrm{~m}$; the buried depth of groundwater is $5.60 \mathrm{~m}$ to $5.90 \mathrm{~m}$, and the foundation pit dewatering is $3 \mathrm{~m}$ below the bottom of the foundation pit.

Although geotechnical engineering problems may never reach a steady state under the influence of external conditions and cycles, it can be regarded as infinitely close to stable state. Hence, this paper uses steady analysis to simulate the actual situation of landfill. And we only need to give the required boundary conditions and various parameters. In order to simulate the actual condition, the soil model was set as saturated/unsaturated model.

Figure 3 shows the finite element model. After establishing the model and assigning finite element regions for each soil layers, it is necessary to assign the physical parameters of each soil layer for each finite element region. The finite element region can be divided into many small calculation units through mesh, and the finite element software will calculate and iterate these meshes. Because of the fast calculation speed, computer is suitable for repeated calculation, thus reducing a lot of manual work. Meanwhile, the grid type used unstructured quadratic \& triangular meshes, and the global grid size was $0.2 \mathrm{~m}$. Grid encryption processing can improve the calculation accuracy, so the grid size of cut-off wall was encrypted to $0.1 \mathrm{~m}$.

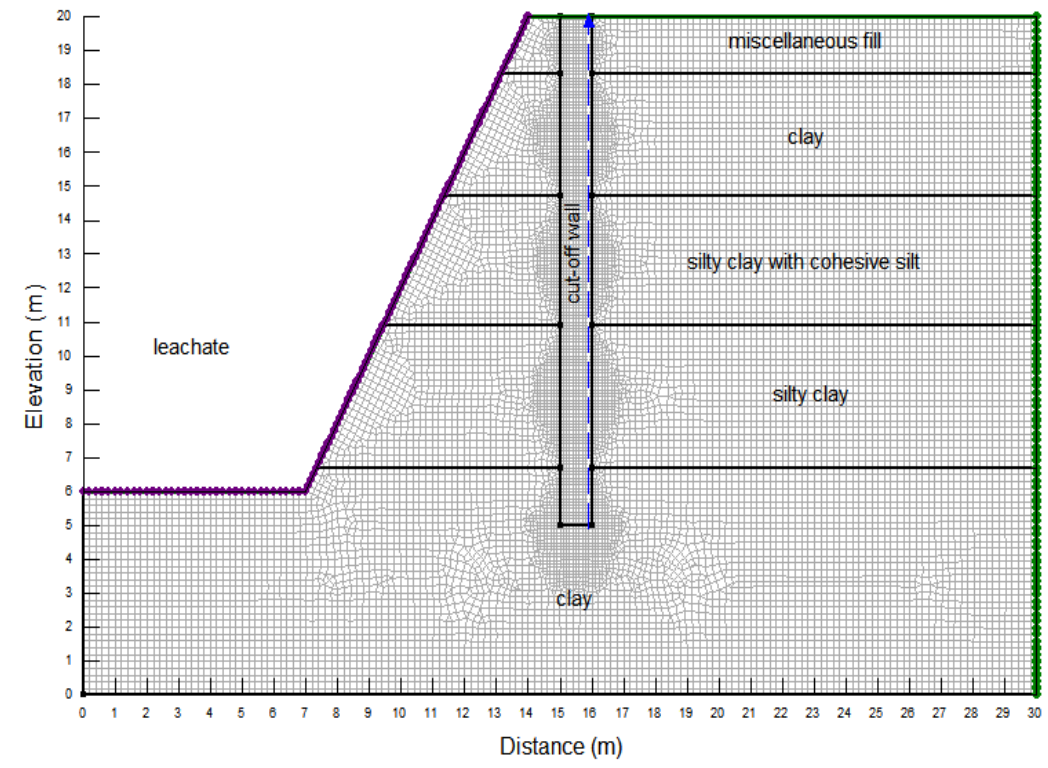

Figure 3. Finite element model and meshing of the cut-off wall

When establishing the model, we should assigned correct boundary conditions. If the boundary conditions are not appropriate, the final analysis results will have one order of deviation [21]. In steady state analysis, there are two ways to specify boundary conditions: specify boundary head or boundary flux. In this analysis, boundary head was assigned as boundary condition, and the simulation result will be seepage flux. The left and right boundary are leachate head and groundwater head, the height difference between left and right water head leads to the seepage in the model. A flux section was drawn in the cut-off wall when the model was established, and its function is to obtain the flow data of the section when leachate seeps through the cut-off wall. Table 2 shows the grid division and boundary conditions. 
Table 2. Grid division and boundary conditions

\begin{tabular}{ccccccc}
\hline $\begin{array}{c}\text { Global } \\
\text { grid size }\end{array}$ & $\begin{array}{c}\text { Grid size of } \\
\text { cut-off wall }\end{array}$ & Grid division type & $\begin{array}{c}\text { Grid } \\
\text { number }\end{array}$ & $\begin{array}{c}\text { Node } \\
\text { number }\end{array}$ & \multicolumn{2}{c}{ Letting of boundary conditions } \\
Left boundary & Right boundary \\
\hline $0.2 \mathrm{~m}$ & $0.1 \mathrm{~m}$ & quadratic \& triangular meshes & 14032 & 14192 & Leachate head & Groundwater head \\
\hline
\end{tabular}

According to the actual situation, two conditions are listed for comparative analysis, which are as follows: (1) The landfill is filled with leachate. (2) The leachate depth is $10 \mathrm{~m}$.

\section{RESULTS}

\subsection{Results of condition 1}

In condition 1, the landfill is filled with leachate, the head boundary condition is $20 \mathrm{~m}$ on the left and $3 \mathrm{~m}$ on the right. The cloud picture of total head is shown in Figure 4 . The simulation results show that the unit width flux is $3.37 \times 10^{-7} \mathrm{~m}^{3} / \mathrm{s}$. The seepage velocity on both sides of the cut-off wall is shown in Figure 5. When leachate passes through the wall, the seepage velocity can be reduced by up to $24.2 \%$, and the maximum values of seepage velocity on both sides appeared at the height of $6 \mathrm{~m}$, which was $4.58 \times 10^{-9}$ $\mathrm{m} / \mathrm{s}$ and $4.29 \times 10^{-9} \mathrm{~m} / \mathrm{s}$ respectively. With the wall height increased, the seepage velocity increased first and then decreased.

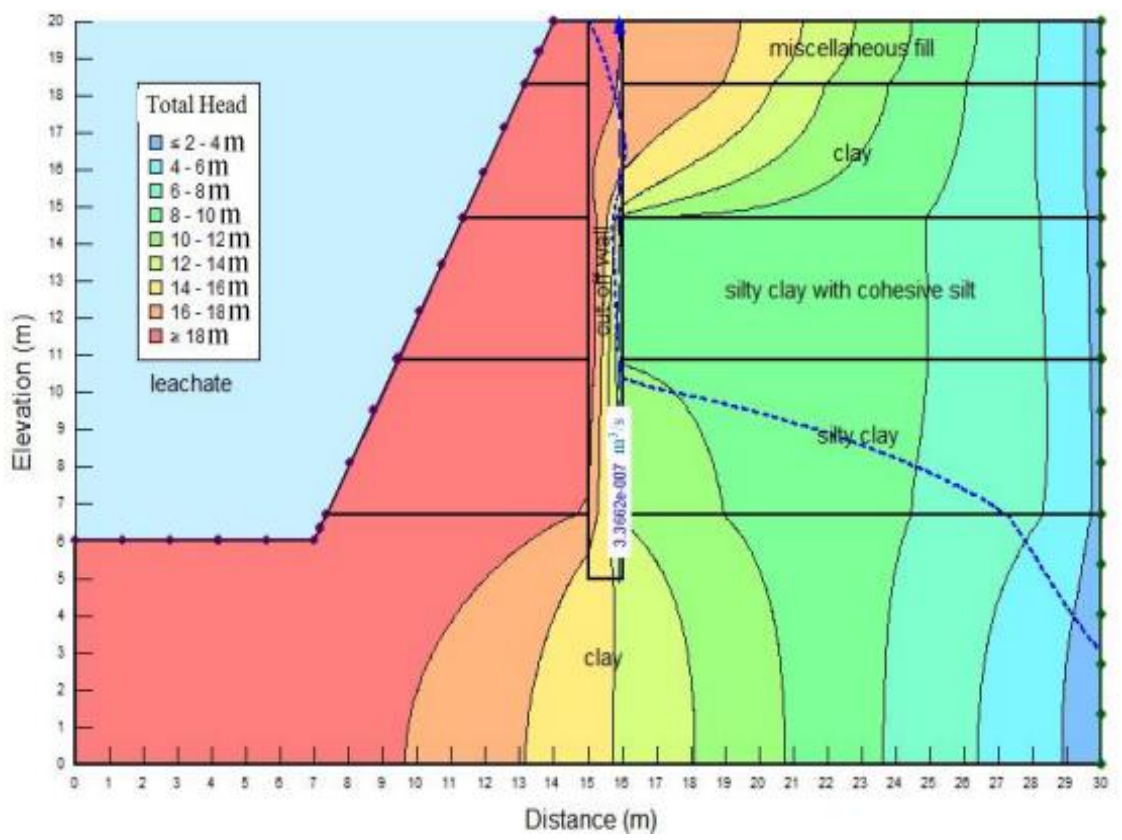

Figure 4. Cloud picture of total head and saturation line

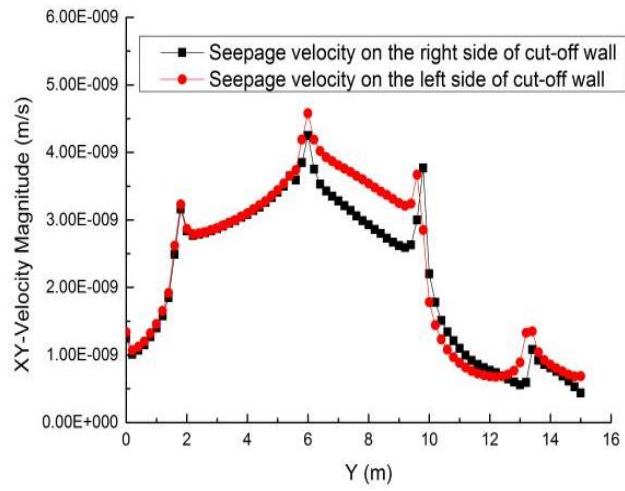

Figure 5. Seepage velocity on both sides of the cut-off wall 
Combined with the equipotential line distribution of the total head, it can be seen that the seepage is mainly concentrated in the middle and lower part of the cut-off wall. Which means that in practical engineering, the anti-seepage performance of these parts should be paid more attention to. The larger the head difference is, the more obvious the seepage action is, so the seepage velocity decreases continuously when the wall height exceeds $6 \mathrm{~m}$. However, because the bottom of the landfill is clay layer which can be used as anti-seepage layer, the seepage velocity increases from 0 to $6 \mathrm{~m}$. At the same time, the slope in the landfill will slow down the seepage velocity of leachate to a certain extent. Therefore, when the leachate seeps into the bottom of the cut-off wall, the seepage velocity of leachate will decrease continuously. Due to the poor soil properties of miscellaneous fill, the seepage velocity at the top of the wall was larger than that in the nearby area. From the seepage velocity curve and cloud picture, it can be inferred that leachate flows around the bottom of the cut-off wall. Therefore, the seepage path becomes longer, which reflects the impermeability of the cut-off wall.

The gradient of cut-off wall is shown in Figure 6, and the maximum gradient of outflow surface of cut-off wall is 18.68 , which meets the relevant standards. According to Technical code for municipal solid waste sanitary landfill(GB50869-2013) [22], $J$ is 10 when the permeability coefficient of cut-off wall $k=10^{-4}$, $J$ is 20 when $k=10^{-5}$ ). Therefore, it is considered that the cut-off wall is safe and will not be damaged by seepage $[23,24]$. For the seepage flow in accordance with Darcy's law, the variation trend of gradient is similar to that of seepage velocity. Therefore, gradient increases at wall height of $0 \sim 9 \mathrm{~m}$ because the soil layer of foundation can be seen as anti-seepage layer; When wall height was $9 \sim 15 \mathrm{~m}$, the water pressure decreases with the increase of wall height; Due to the poor permeability of miscellaneous fill, the gradient on the top of the wall is larger than nearby areas. In order to ensure the safety, it is necessary for project to reduce the height of saturation line as much as possible. It can be seen from the Figure 4 that there is a 10.3 $\mathrm{m}$ drop between the infiltration point and overflow point of the saturation line, which indicates that the cutoff wall can effectively reduce the height of the saturation line to improve the safety of the project.

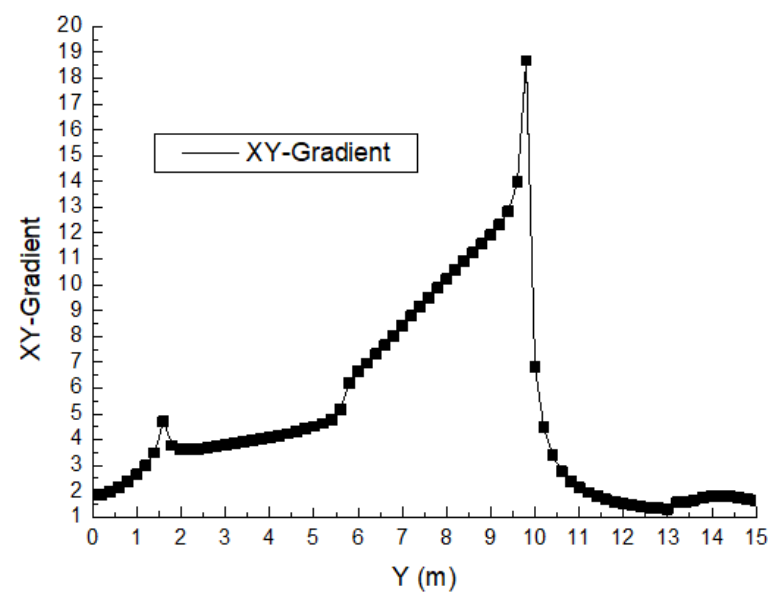

Figure 6. The change of seepage gradient with wall height

\subsection{Results of condition 2}

In condition 2, the leachate depth is $10 \mathrm{~m}$, the head boundary condition is $16 \mathrm{~m}$ on the left and $3 \mathrm{~m}$ on the right. The cloud picture of total head is shown in Figure 7. The simulation results show that the unit width flux is $1.98 \times 10^{-7} \mathrm{~m}^{3} / \mathrm{s}$. The seepage velocity on both sides of the cut-off wall is shown in Figure 8 , when leachate passes through the wall, the seepage velocity can be reduced by up to $27 \%$, and the maximum values of seepage velocity on both sides appeared at the height of $6 \mathrm{~m}$, which was $2.98 \times 10^{-9} \mathrm{~m} / \mathrm{s}$ and $2.79 \times 10^{-}$ ${ }^{9} \mathrm{~m} / \mathrm{s}$ respectively. With the wall height increased, the seepage velocity increased first and then decreased. The gradient of cut-off wall is shown in Figure 9, and the maximum gradient of cut-off wall is 13.85, which is in line with national standards. 


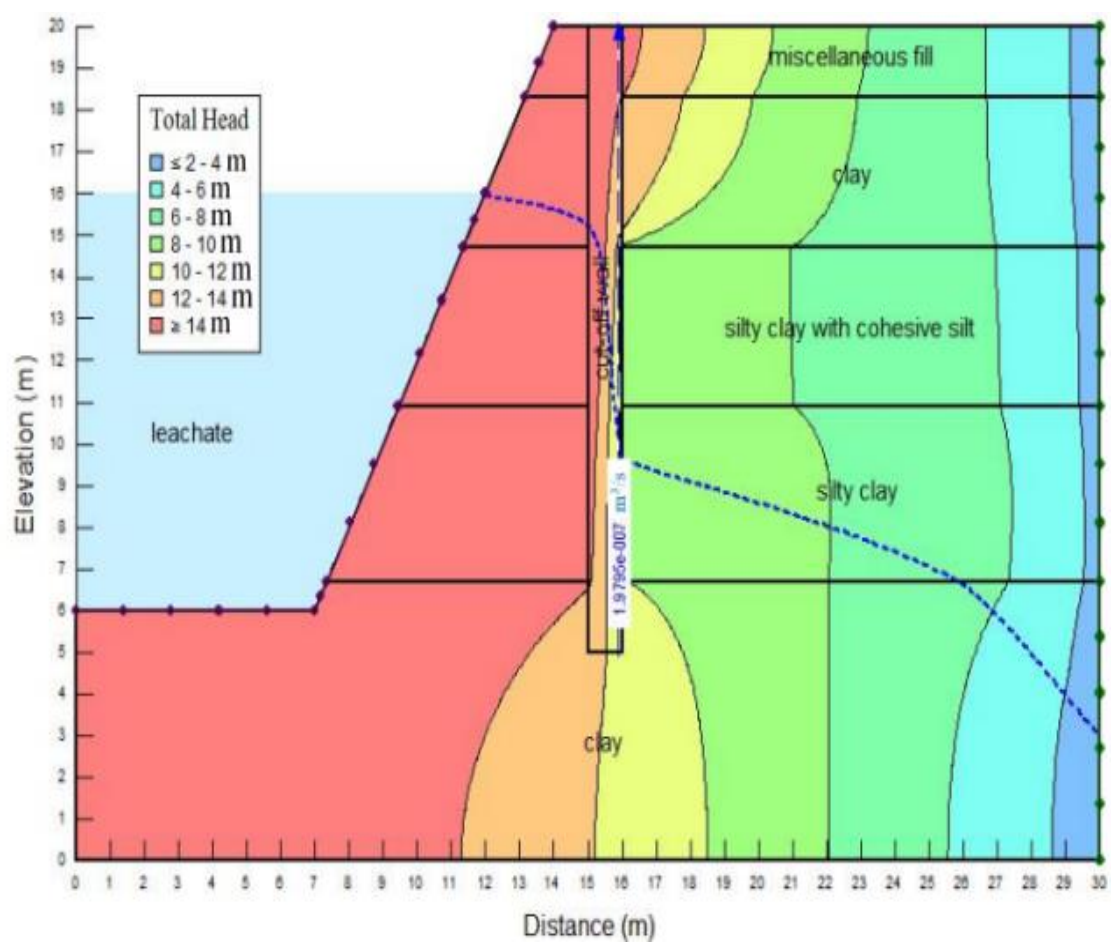

Figure 7. Cloud picture of total head and saturation line

In this condition, there is a $6.4 \mathrm{~m}$ drop between the infiltration point and overflow point of the saturation line, and the saturation line is lower than that of condition 1 . The soil below the saturation line is saturated, so under the influence of seepage flow, its shear strength, seepage stability and the stress on the wall will be greatly affected. This change will affect the safety of cut-off wall and surrounding soil [25]. In actual projects, it is necessary to reduce the height of leachate level to lower the height of the saturation line.

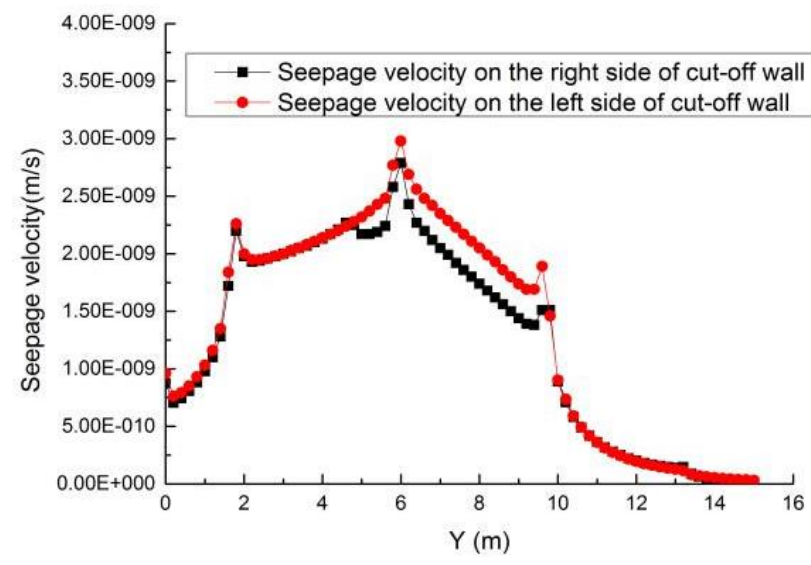

Figure 8. Seepage velocity on both sides of the cut-off wall

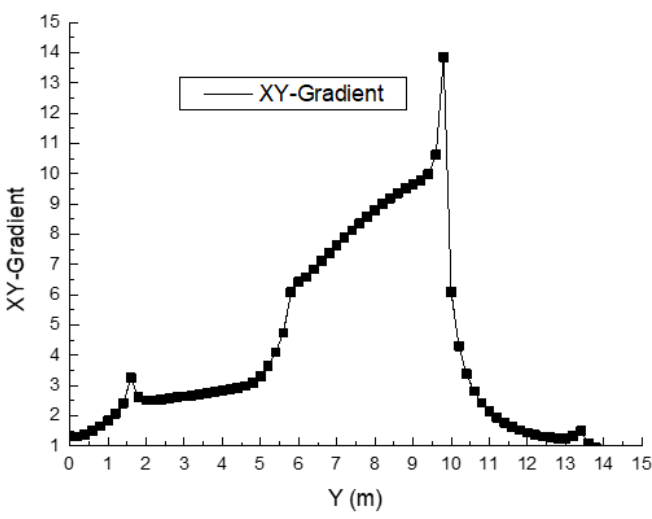

Figure 9. The change of seepage gradient with wall height

\subsection{Discussion}

The seepage field of leachate in cut-off wall and surrounding soil can be obtained accurately and intuitively by using finite element method. When the boundary conditions are different, the results show similar regulations, but the differences caused by head difference are as follows: In condition 2, the leachate water level is lower than that of condition 1, which leads to smaller difference of total head. Because the seepage velocity is proportional to the head difference, the seepage velocity of condition 2 is smaller than 
that of condition 1. Also, the unit width flux is smaller, means that smaller head difference will lead to smaller infiltration capacity. For the seepage flow in accordance with Darcy's law, the variation trend of gradient is similar to that of seepage velocity, so smaller head difference lead to smaller gradient.

The values of some points have a sudden change because material properties at the boundary change a lot. Although the finite element method is relatively accurate, the error is still inevitable [26]. The computer finite element software regards the soil layer model as isotropic when parameters such as material properties be inputted. But in fact, the soil is anisotropic, and its horizontal coefficient and vertical permeability coefficient are different. In addition, the impact of rainfall, garbage filling in the landfill and surface pressure around the landfill were not considered in the analysis, so the simulated value will have certain deviation from the actual result.

\section{CONCLUSION}

This paper studied the permeability of cut-off wall in landfill on the basis of the current seepage analysis of dams and other water conservancy projects. With the help of finite element software, a numerical analysis was carried out on the practical engineering cut-off wall constructed with PBFC anti-seepage slurry. This paper mainly studied the seepage on cut-off wall of different leachate levels, the conclusions of this paper are as follows:

The seepage velocity of leachate decreases with the increase of wall height. In practical engineering, the seepage velocity increases first and then decreases with the increase of wall height due to the blocking effect of stratum and inner slope. After the leachate enters the cut-off wall, the seepage velocity of leachate decreases by $24.2 \%$ and $27 \%$ respectively, which indicates that the cut-off wall can effectively reduce the seepage velocity of leachate. The seepage is mainly concentrated in the middle and lower parts of the wall, so more attention should be paid to these parts in practical engineering.

The results of numerical simulation show that the gradient are 18.68 and 13.85 respectively, which are both within the safe range, the overflow point of the saturation line on the cut-off wall is much lower than the immersion point, which indicates that the cut-off wall can improve the permeability stability of the surrounding environment.

When the head difference decreases, the seepage velocity and gradient will also decrease accordingly. According to the simulation results, when the water head difference decreases by 4 meters, the difference between the elevation of infiltration point and overflow point of phreatic line decreases by 3.3 meters. Therefore, drainage measures can be set to reduce the water level of leachate, so as to reduce the height of saturation line.

\section{ACKNOWLEDGEMENT}

This research was financially supported by the National Natural Science Foundation of China (Grant No. 51678083).

\section{REFERENCES}

[1] Qi-Qi Zhang, Bao-HuTian, Xuan Zhang, Abbas Ghulam, Cheng-Ran Fang, Ruo He, "Investigation on characteristics of leachate and concentrated leachate in three landfill leachate treatment plants," Waste Management, vol. 33, no. 11, pp. 2277-2286, 2013.

[2] M.S. Hossain, K. K. Penmethsa, L. Hoyos, "Permeability of municipal solid waste in bioreactor landfill with degradation," Geotechnical and Geological Engineering, vol. 27, no. 43, pp. 43-51, 2009.

[3] Minhee Kim, Seunghun Hyun, Jung-Suk Sung, "Adsorptive attenuation of ferrocyanide from seepage water in landfill clay liners,” Environmental Earth Sciences, vol. 68, pp. 2007-2014, 2013.

[4] R. Kadambala, Jon Powell, Karamjit Singh, Timothy G Townsend, "Evaluation of a buried vertical well leachate recirculation system for municipal solid waste landfills," Waste Management \& Research Journal for a Suistainable Circular Economy, vol. 34, pp. 1300-1306, 2016.

[5] G. Dai, J. Zhu, G. Shi, "Analysis on the basic properties of PBFC antiseepage slurry in landfill," Applied Ecology and Environmental Research, vol. 16, pp. 7657-7667, 2018.

[6] J. B. Rittgers, A. Revil, T. Planes, M. A. Mooney, A.R. Koelewijn, "4-D imaging of seepage in earthen embankments with time-lapse inversion of self-potential data constrained by acoustic emissions localization," Geophysical Journal International, vol. 200, no. 2, pp. 758-772, 2015.

[7] H. Ueda et al., "Numerical Simulation on Magnetic Field Generated by Screening Current in 10-T-Class REBCO Coil," in IEEE Transactions on Applied Superconductivity, vol. 26, no. 4, pp. 1-5, Jun 2016, Art no. 4701205, doi: 10.1109/TASC.2016.2535965.

[8] Muthusamy Karthikeyan, Thiam-Soon Tan, Kok-Kwang Phoon, "Numerical oscillation in seepage analysis of unsaturated soils," Canadian Geotechnical Journal, vol. 38, pp. 639-651, 2001.

IAES Int J Rob \& Autom, Vol. 10, No. 1, March 2021: 59-67 
[9] G.X. Zhang, "Study on numerical simulation method used in analyzing the effect of seepage pressure in continuous medium with pores on deformation and stress," Journal of Hydraulic Engineering, vol. 48, pp. 640-650, 2017.

[10] Fukuchi Tsugio, "New high-precision empirical methods for predicting the seepage discharges and free surface locations of earth dams validated by numerical analyses using the IFDM," Soils and Foundations, vol. 58, no. 2, pp. 427-225, 2018.

[11] L. Shi, G.H. Sun, "Improvement of the finite-element-based limit equilibrium method to include changes in groundwater: a case study of a deforming bank slope from the Three Gorges Reservoir," Environmental Earth Sciences, vol. 77, no. 333, 2018.

[12] D. M. Pedroso, "Enriched Finite Element for Modelling Variable Boundary Conditions in Unsaturated Seepage Problems," Applied Mechanics and Materials, vol. 846, pp. 372-377, 2016.

[13] Shivakumar S. Athani, Shivamanth, C. H. Solanki, G. R. Dodagoudar, "Seepage and Stability Analyses of Earth Dam Using Finite Element Method," Aquatic Procedia, vol. 4, pp. 876-883, 2015.

[14] Chongbin Zhao, P. Schaubs, B. E.Hobbs, "Computational simulation of seepage instability problems in fluidsaturated porous rocks: potential dynamic mechanisms for controlling mineralisation patterns," Ore Geology Reviews, vol. 79, pp. 180-188, 2016.

[15] Zuoan Wei, Guangzhi Yin, Ling Wan, Guangzhi Li, "A case study on a geotechnical investigation of drainage methods for heightening a tailings dam," Environmental Earth Sciences, vol. 75, no. 106, 2016.

[16] Guozhong Dai, Yanmin Sheng, Shujin Li, Yaxing Zhang, "Experimental study on mechanical properties of antiseepage slurry in landfill," Modern Physics Letters B, vol. 32, no. 34n36, 2018.

[17] Guozhong Dai, Weicheng Shi, Xiaoshu Jiang, Guicai Shi, Yaxing Zhang, "Study on the antiseepage mechanism of the PBFC slurry for landfill site," International Journal of Modern Physics B, vol. 31, no. 1744087, pp. 16-19, 2017.

[18] Y. Zhang, "Derivation of basic differential equation of saturated and unsaturated seepage," Henan Water Resources \& South-to-North Water Diversion, vol. 14, pp. 76-79, 2015.

[19] Lai Yuanming, Liu Songyu, Wu. Ziwang, Wu Yaping, J. M. Konrad "Numercial simulation for the coupled problem of temperature and seepage fields in dams," Journal of Hydraulic Engineering, vol. 40, no. 5, pp. 631-635, 2001.

[20] Gang Liu, Fuguo Tong, Bin Tian, "A Finite Element Model for Simulating Surface Runoff and Unsaturated Seepage Flow in the Shallow Subsurface," Hydrological Processes, vol. 33, no. 26, pp. 3378-3390, 2019.

[21] Wenxing Jian, Qiang Xu, Hufeng Yang, Fawu Wang, "Mechanism and failure process of Qianjiangping landslide in the Three Gorges Reservoir," Environmental Earth Sciences, vol. 72, pp. 2999-3013, 2014.

[22] GB50869-2013, "Technical code for municipal solid waste sanitary landfill," Beijing: China Planning Press, 2013.

[23] Xiangfeng Lv, Zhenwei Wang, Jianguo Wang, "Seepage-damage coupling study of the stability of water-filled dump slope," Engineering Analysis with Boundary Elements, vol. 42, pp. 77-83, 2014.

[24] Rong Yang, Zengguang Xu, Junrui Chai, Yuan Qin, Yanlong Li, "Permeability test and slope stability analysis of municipal solid waste (MSW) in Jiangcungou Landfill, Shaanxi, China," Journal of the Air \& Waste Management Association, vol. 66, no. 7, pp. 655-662, 2015.

[25] Yong-Xia Wu, Shui-Long Shen, Ye-Shuang Xu, Zhen-Yu Yin, "Characteristics of groundwater seepage with cut-off wall in gravel aquifer. I: Field observations," Canadian Geotechnical Journal, vol. 52, pp. 1539-1549, 2015.

[26] J. Chaskalovic, F. Assous, "Data mining and probabilistic models for error estimate analysis of finite element method," Mathematics and Computers in Simulation, vol. 129, pp. 50-68, 2016. 